\title{
Política indigenista y política indígena pilagá en materia de tenencia de la tierra
}

\author{
Indigenist policy and indigenous Pilagá policy on land tenure
}

Marina Matarrese marinamatarrese@hotmail.com

http://orcid.org/0000-0001-7923-2135

Facultad de Filosofía y Letras; Universidad de Buenos Aires/ Consejo Nacional de Investigaciones Científicas y Técnicas (Argentina)

\section{Resumen}

Como corolario del proceso de conquista y colonización de la región del Gran Chaco argentino, acaecida desde fines del siglo XIX, los indígenas han sufrido un proceso de arrinconamiento territorial. En este sentido, uno de los derechos, reclamos y reconocimientos más relevantes en materia de derechos indígenas a nivel internacional, nacional y provincial de Formosa giró en torno a la tenencia de la tierra. En el presente artículo se analizará cómo, de la mano de los reconocimientos normativos se accionaron dos políticas que pueden analizarse en términos de, por un lado la política indigenista de tenencia de la tierra y de una serie de procedimientos burocráticos para operacionalizar dichas políticas en sintonía con la normativa vigente. Por el otro, y como parte de las políticas indígenas de los pilagá, se construyó en torno al territorio un discurso legitimador de dicha tenencia en tanto guardianes de la naturaleza.

Palabras clave: Política indígena; política indigenista; pilagá; territorio; discurso legitimador; 
Formosa.

Abstract

As part of the Gran Chaco argentino process of conquest and colonization that took place at the end of the 19th century, the indigenous people suffered a territorial backing. In this sense, one of the most relevant rights, claims and recognitions in the field of indigenous rights is land tenure. In this article we will analyze on the one hand, the indigenous land tenure policy of de Formosa province and a series of bureaucratic procedures to operationalize the current regulations. On the other hand, and as part of the policies of the Pilagá, a discourse legitimizing this tenure as guardians of nature around the territory.

Keywords: indigenous politics; indigenist politics; pilagá; territory; legitimizing discourse; Formosa.

Los asentamientos, o parajes fijos actuales de los grupos de familias extensas (Braunstein, 1984) en una localidad determinada, constituyen el remanente del territorio indígena que los pueblos originarios supieron recorrer hasta principios de siglo XX en el Gran Chaco argentino. Estos asentamientos fijos han sido reconocidos por el Estado bajo la denominación de "comunidades indígenas" en el marco de un proceso de constitución de los indígenas como sujetos colectivos con derechos especiales. En efecto, desde el retorno de la democracia en 1983, se legisló un profuso marco a nivel nacional -la Ley Nro. 23302/85 sobre Política Indígena y Apoyo a las Comunidades Aborígenes, la reforma en 1994 de la Constitución Nacional, la Ley Nro. 26160/6 de emergencia en materia de posesión y propiedad de la tierra y sus respectivas prórrogas; Ley 26554/09; Ley Nro. 26894/13 y Ley Nro. 27400/17 y la reforma del Código Civil de 2015 que en el artículo 18 reconoce a las comunidades indígenas en tanto persona jurídica especial que tiene capacidad de poseer propiedad y posesión comunitaria de las tierras que tradicionalmente ocupan. Asimismo este artículo está dentro del Título "Derechos y Bienes" y no dentro del Libro IV destinado a los Derechos Reales, otorgándole una categoría especial. Cabe destacar que la ley de promulgación de esta reforma Nro. 26994/14 se estipula que "los derechos de los pueblos indígenas, en particular la propiedad comunitaria de las tierras que tradicionalmente ocupan y de aquellas otras aptas y suficiente para el desarrollo humano, serán objeto de una ley especial". 
En cuanto al plano internacional los tratados que rigen en materia indígena son la Declaración de las Naciones Unidas sobre los Derechos de los Pueblos Indígenas (2007), el Convenio 169 sobre Pueblos Indígenas y Tribales elaborado por la Organización Internacional del Trabajo (OIT) que comenzó a regir en 2001 y la Convención Americana sobre Derechos Humanos.

Específicamente los pilagá constituyen un pueblo indígena que habita en el centro de la provincia de Formosa, y según datos proporcionados por el INDEC (2010) suman unas 4400 personas en unas 22 comunidades reconocidas por el Estado. Estas comunidades son el resultado de un largo proceso de conquista y colonización de la región que data de fines del siglo XIX. Este proceso estuvo caracterizado por la sedentarización y relocalización forzada de los indígenas (Beck, 1994; Iñigo Carreras, 1983; 1984; Lagos, 1998; 2000; Lois, 2002; Martínez Sarasola, 2005; Trinchero, 2000), el cercenamiento de los territorios debido al proceso de privatización surgido del avance del frente agro-ganadero (Beck, 1992; 1994; Iñigo Carreras, 1983; 1984; Lagos, 1998; 2000; Lois, 2002; Trinchero, 2000) y la explotación de los aborígenes como mano de obra barata (Gómez, 1939; Gordillo, 1992; 2004; 2006; Halperín Donghi, 1982; Iñigo Carreras, 1983; 1984; Lagos, 1998; 2000; Martínez Sarasola, 2005; Trinchero, 2000).

Desde 1984, Formosa comenzó una política indigenista de entrega de tierras a los tres pueblos indígenas (toba, wichí y pilagá) de la provincia a partir de la sanción de la Ley Nro. 426/85. Asumo una distinción teórica propuesta por Diana Lenton (2010) según la cual por un lado, la política indigenista corresponde a la política del Estado referida a los pueblos indígenas en planes, programas, leyes, normativa general e instituciones, ente otros. Por otro lado, entiendo a la política indígena como las políticas de representación y diversas estrategias de participación y /o autonomización de las organizaciones de militancia y/o colectivos de pertenencia indígena (Lenton, 2010). A partir de estas categorías, los interrogante que inspiran el presente artículo discurren en un doble registro, por un lado dar cuenta cómo se operacionalizó esta política indigenista en materia de tierra en Formosa y qué prácticas burocráticas y papeleos implicó. A contraluz de este aspecto por otro lado, nos proponemos poner en relieve la política pilagá, es decir las adecuaciones y estrategias de los indígenas para ser destinatarios de una de esas políticas en la provincia, entre las que se encuentran las construcciones discursivas como un instrumento más de legitimación de su derecho al territorio. 


\section{Pedidos y papeles: un aspecto de la política indigenista}

Formosa a partir de la sanción de la Ley Nro. 426/84 comenzó a transferir la tenencia de la tierra a nombre de las comunidades indígenas de los tres grupos reconocidos por la provincia. En total se titularon casi 290.000 hectáreas. Los wichí recibieron el $68 \%$ de las tierras reconocidas (198.300 ha.), los qom el $20 \%$ de esas tierras —es decir 58.400 hectáreas (ha.) y los pilagá titularon 33.290 ha. (11.74\%) según datos proporcionado por Dirección de Tierras del Instituto de Comunidades Aborígenes (ICA) de la provincia de Formosa (Matarrese, 2011). Cabe aclarar que el ICA es el instituto creado por esa ley, que centraliza la gestión de todas las políticas y asuntos indígenas en la provincia.

Según lo establecido por esta normativa: "Cuando una comunidad aborigen tuviera reconocida su personería jurídica, se le transferirá la tierra en forma gratuita, libre de todo gravamen" (Ley 426/84; Cap. II, art. 15). Es decir que al momento de sancionar la ley una condición para la transferencia de la tierra era la inscripción de su personería jurídica en la Dirección de Personería Jurídica (DPJ) de la Provincia. A tales fines, según reza el instructivo realizado por esta dependencia del Estado (1), para su constitución debía tener lugar una Asamblea Constitutiva (por única vez y a los fines dicha inscripción), una Asamblea Ordinaria (reunión anual para presentar Memoria de Balance y Renovación de la Comisión Directiva y Comisión Revisora de Cuentas, según corresponda) y una Asamblea Extraordinaria (cuando la comunidad lo crea necesario para la reforma parcial o total de los Estatutos). Asimismo, se debía presentar Acta de Asambleas, Estatuto Social, Declaración Jurada de Patrimonio, Libros reglamentarios (2) y una estampilla de la Dirección General de Rentas de la provincia. Son estas mismas tramas de procesos las que construyen y a su vez normalizan un orden procedimental, así como se estipula cuáles son las organizaciones desde las cuales diligenciar determinados pedidos así como las posibles soluciones o respuestas legalmente correctas en materia de la tierra que son esperables. Para este engorroso proceso, se redactó un Instructivo de la Dirección de Personería Jurídica para la Inscripción de Comunidades Aborígenes. Este instructivo, que cito a continuación, contiene cartas modelo de presentaciones y pasos a seguir:

El sistema de organización jurídica, sus requisitos y exigencias no es propio de su cultura, les resulta complicado, difícil de entender y difícil de realizar, pero es un trámite necesario para poder tener los beneficios que de otra manera hoy por hoy sería imposible. Llegará en tiempo en que las comunidades tengan una organización propia y sólida y con recurso humano capacitado como para proponer modos, formas según sus usos y costumbres, 
combinando lo jurídico, lo legal y lo que es conveniente para las comunidades indígenas, es decir, sus usos y costumbres (Dirección de Personería Jurídica, 2010).

Si bien se reconoce que parte del proceso es reconocidamente ajeno a la organización de los indígenas, se justifica a fin de construirse a través del mismo en beneficiarios de dichas políticas de tenencia de la tierra. Además, se responsabiliza a los pueblos originarios por la inadecuación entre su organización y la estipulada por el Estado, dada la falta de "recurso humano capacitado" para proponer modos que articulen el marco jurídico con sus "usos y costumbres". Esta reconocida inadecuación, conlleva numerosos inconvenientes tales como que frecuentemente las autoridades de estas organizaciones tienen los mandatos vencidos, 0 el llenado de papeles es incorrecto dado que se ha usado lápiz, o bien hay reiteración de personas en cargos distintos, entre otros. Su consecuencia es que las comunidades frecuentemente no tienen los "papeles en regla" a la hora de hacer un pedido ante el ICA o alguna ONG. Al respecto un dirigente pilagá de la comunidad de Campo del Cielo, en el marco del Proceso de Participación de los Pueblos Indígenas sostuvo:

\footnotetext{
...queremos que el gobierno nos reconozca una personería jurídica simple para los pueblos indígenas, porque no sabemos hacer el balance cada dos años, ni manejar los libros, ni hacer memoria, ni hacer líneas de acción, porque no es costumbre nuestra, porque no hemos nacido para estos trabajos que son manejos de papeles (PPI, 2003: 236).
}

Este proceso de inscripción de la comunidad, que es referido por este pilagá, como un "manejo de papeles", ya lleva más de 25 años. En torno al mismo y a esta "demanda planificada" — tal como Pantaleón (2005) define, para el análisis de Desarrollo Social en Salta, a las demandas cuyos destinatarios son sectores o grupos de población, a diferencia de "demandas espontáneas" para necesidades individuales y específicas - se constituyeron una serie de prácticas administrativas que presuponen determinados saberes. En consecuencia, aquellos dirigentes que lograron posicionarse como interlocutores frente a los organismos de gobierno, generalmente han sido quienes han accedido a un grado de educación formal o a una red de compromisos políticos impuestos por representantes del Estado (Spadafora, Gómez y Matarrese, 2010).

Estos procesos al tiempo que normalizan modos de pedir, generan una jerarquía al interior de los demandantes, en este caso los indígenas en función de determinados saberes burocráticos o culturales. A su vez estos "papeles" no son sólo metáforas para antropologizar analíticamente 
determinados procesos (Pantaleón, 2005), antes bien son instrumentos que materializan las transformaciones que en torno a la tenencia de la tierra de los grupos indígenas han acaecido desde la década de los ochenta. Con todo, la gran mayoría de las comunidades obtuvo su personería jurídica en la provincia. En el caso pilagá, las 23 comunidades reconocidas debieron adaptar sus organizaciones a las formas reguladas por esta ley.

Dada la dinámica que adquirió la lucha política pilagá en la última década, la obtención de la personería jurídica, se convirtió en uno de los puntos centrales de estas negociaciones políticas locales. Tal es el caso de la Federación de Comunidades del Pueblo Pilagá que se conformó entre 2001 y 2003, y articula políticamente a las veintitrés comunidades. Está dirigida por un triunvirato electivo, formado por representantes de los ancianos, de las mujeres y de los hombres adultos. Tras un sinnúmero de obstáculos para inscribirse en el ámbito provincial, a pesar de haber iniciado este trámite el 13 de abril de 2007, obtuvo su personería jurídica en la esfera nacional en enero de 2012 al inscribirse en el Registro Nacional de Comunidades Indígenas (RENACI), perteneciente al Instituto Nacional de Asuntos Indígenas (INAI). Este registro nacional, recién en 2012 se reglamentó el marco regulatorio para que las comunidades se inscriban. Cabe aclarar que tampoco es sencillo este proceso que consta de tres pasos debido a imposibilidades que por empezar son la distancia (Matarrese, 2011) y a la reticencia a nivel provincial con respecto a la actuación federal en todos los asuntos referidos a la tenencia de la tierra, tal como se manifiesta en la aplicación de leyes nacionales en la materia (por ejemplo, Ley Nro. 26160/06 y sus prórrogas Ley 26554/09, Ley 26894/13 y Ley 27400/17). Con todo la Reforma del Código Civil de 2015 con respecto de la personería jurídica de las comunidades indígenas fue alentadora y resta esperar la sanción de la ley especial y las modificaciones operativas que conlleve.

Lo consignado hasta aquí constituye el derrotero de la tramitación de la personería jurídica en Formosa, primer paso para comenzar con el proceso de titulación de tierras fiscales a nombre de las comunidades. Una vez reconocida la personería (artículo 15), la titulación de tierra y los pasos a seguir se explicitan en los artículos 15, 16 y 17 de la Ley 426/84 e involucra a diversos organismos provinciales. La comunidad le solicita al ICA la tierra elegida, especificando su ubicación y superficie aproximada. El pedido es presentado en Mesa de Entradas del Instituto, y allí es elevado al Departamento de Tierras del ICA.

A su vez, este Departamento transfiere el pedido al Instituto Provincial de Colonización y Tierras Fiscales (IPCyTF) para saber si es factible o no su otorgamiento (art. 17, a). Esta constatación consiste en averiguar el estado legal de la tierra, como por ejemplo, si en ese momento está libre de ocupación o si existen otros interesados en la superficie solicitada. 
Si las tierras fiscales son aptas para la titulación se abre un expediente dándole curso al pedido de la comunidad y se envía una comisión de inspección y relevamiento coordinada entre el ICA y el IPCyTF a fin de realizar la inspección técnico-administrativa y un plano de encuadramiento (art. 17, b). Luego el IPCyTF eleva un informe al ICA (art. 17, c) con la documentación faltante de la asociación civil para poder concretar la titulación. Cumplidos estos requisitos, el IPCyTF autoriza legalmente -mediante Permiso de Ocupación- la instalación de la comunidad en las tierras solicitadas (art 17, d). En el mismo Permiso se compromete al ICA a realizar la mensura, deslinde y amojonamiento (art 17, e). Para ello previamente el Instituto le solicita al IPCyTF la Instrucción de Mensura, para establecer la ubicación y la superficie exactas. Una vez que el equipo del ICA se comisionó y confeccionó los planos, éstos son enviados a la Dirección de Catastro Territorial para su aprobación (ver plano de mensura adjunto). 


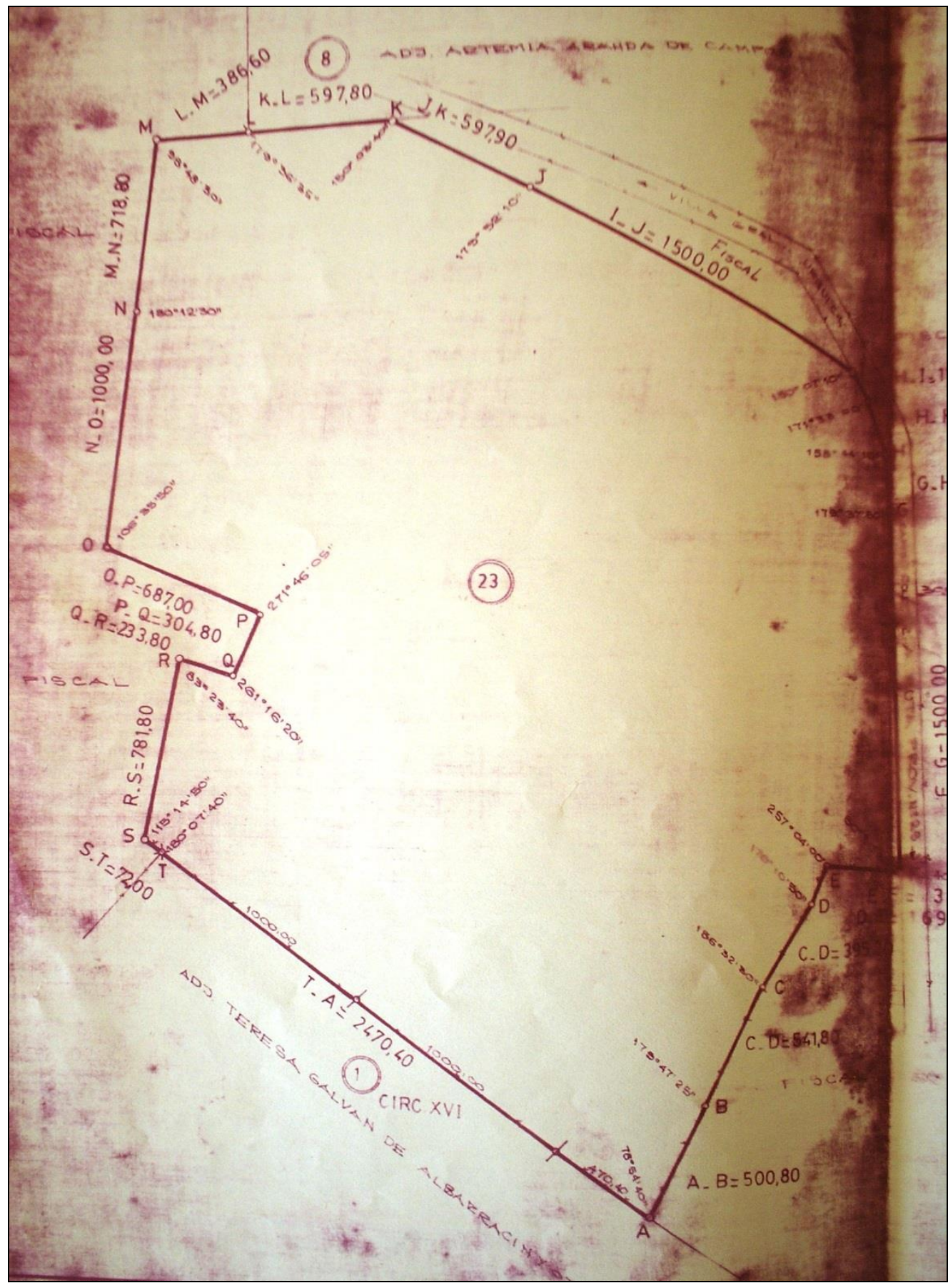

Figura 1: Plano de mensura y relacionamiento de Qom Pi, una comunidad periurbana pilagá, 1986. Fuente: Instituto Provincial de Colonización y Tierras Fiscales. 
Con los planos aprobados el ICA envía al IPCyTF todos los requisitos exigidos, y de acuerdo a la Ley Nro. 426/84, éste mediante una Resolución ordena su escrituración y habilita el asentamiento de la comunidad (art. 17, inc. g). Finalmente se envía esta Resolución a la Fiscalía de Estado para que emita dictamen acerca de ella y, de no existir inconvenientes, se la envía a la Escribanía Mayor de Gobierno para su escrituración que es rubricada por el gobernador de la provincia (3).

Estos múltiples pasos ponen de relieve que no es nada sencillo hacerse del título de tierras. Este camino para la titulación por las comunidades desde el inicio de un pedido formal hasta su reconocimiento también oficial si bien está explicitado en tanto instancias transparentes, no dejan de ser manipuladas y accionadas de acuerdo a la capacidad y posición en el espacio de dominación que van asumiendo los diversos agentes intervinientes cuanto el marco de la política en el que se está inserto, más aún cuando desde el Estado provincial no hay voluntad política para entregar "más" tierras a los indígenas.

En la actualidad en la Dirección de Tierras del ICA hay veinte pedidos de tierras pendientes (entre ampliaciones, nuevos pedidos y la regularización de ocupaciones). Desde esta Dirección argumentan que estos pedidos no se están tramitando por falta de medios del Instituto, tales como la carencia de vehículo para llegar a las zonas reclamadas. Esta falta de medios implica falta de disponibilidad política para concretar las titulaciones, sumado a la poca predisposición del IPCyTF que argumenta que no hay más tierras fiscales disponibles. En definitiva, cada una de las instancias administrativas explicadas puede utilizarse para dilatar la titulación y dichas dilaciones también forman parte de la implementación de una política indigenista.

Este proceso también es pasible de ser analizado en los términos que Gastón Gordillo (2009), ha definido en tanto "clientelización de la etnicidad", entendidas como las relaciones de dominación que se han instalado en las comunidades indígenas y en torno a determinados beneficios en el marco de políticas indigenistas o bien como pieza de cambio de políticas partidarias generando espacios de control, así como espacios de resistencia y acomodamiento, desde los cuales los indígenas canalizan sus demandas como actores activos. En efecto, de manera paralela a estas políticas estatales, los indígenas como parte de su política por un lado adquieren saberes y se van amoldando estratégicamente a los requerimientos del Estado para poder ser destinatarios efectivos de estas políticas indigenistas y por otro han construido un discurso que los legitima en tanto los dueños preexistentes de esas tierras y poseedores "naturales" de determinados territorios dado un saber ancestral que analizo en el siguiente apartado. 


\section{Legitimaciones discursivas: una clave de la política indígena}

A partir de la década de 1990 el territorio en la Argentina se transformó en un emblema de la lucha por los reconocimientos de los derechos de los pueblos indígenas (Gordillo y Hirsch, 2003; 2010). Los indígenas adoptaron el término territorio, habiendo constatado la estrechez de las tierras concretamente tituladas y en un intento de dar cuenta de aquellas que les permitieran continuar con sus modos de vida.

Los pilagá titularon 33.290 hectáreas en los 23 asentamientos reconocidos por el Estado. Estos asentamientos están ubicados en la región central de la provincia de Formosa pero no están dispuestos de manera continua. De este modo, y tal como se analizó en Matarrese (2011; 2013; 2017) existe una tensión entre el modo de utilizar o recorrer el territorio por los pilagá y la titulación reconocida por el Estado provincial. Parte de esta tensión radica en una concepción diferencial entre los pilagá, para quienes el territorio es relacional y parte constitutiva de su identidad y la concepción del sistema legal argentino para el que la tierra es de carácter privado, civil y exclusivo.

Dado el grado de ocupación de la zona en 1985 y el requerimiento para la titulación de la tierra de la condición fiscal y de su no-ocupación por parte de pobladores no indígenas o qoselek, se obstruyeron la reivindicación y obtención de los territorios históricamente utilizados por los pilagá y particularmente de los más fértiles y estratégicos (Spadafora et al, 2010). En mayor medida se titularon solamente las tierras en las que se encontraban asentados en ese momento histórico particular. Como afirman García Hierro y Surrallés con respecto a las titulaciones de los indígenas de las tierras bajas: "...las actuales tierras tituladas vienen a ser el resultado de toda una larga historia de pequeños o grandes enfrentamientos, así como de arreglos, renuncias, resignaciones y adaptaciones hasta hacerla confusa incluso para los mismos pobladores" (2004: $11)$.

Los pilagá, como parte de su estrategia política, han ido adaptando, sus instituciones y reclamos a cada coyuntura, para conseguir asegurarse algún grado de legalidad con respecto a la tenencia de la tierra. Con todo, si los pilagá han aceptado titular las tierras en carácter de propiedad privada y de manera intermitente, ha sido para asegurarse su tenencia legal frente a otros posibles "dueños" y como parte de una estrategia política antes que por la capacidad de dicha regulación de dar cuenta de su vinculación con el territorio.

De manera paralela a la titulación, la política pilagá, en coincidencia con el discurso de la política étnica internacional constituyó al término territorio como parte de un nuevo lenguaje étnico- 
político a la hora de defender sus derechos. A través de denuncias de privatizaciones de las tierras circundantes, pedidos de ampliación de las comunidades y disputas por lograr una prometida y siempre insuficiente participación en los denominados "proyectos de desarrollo" fueron significando al territorio con diversas intensidades y matices, casi comparables con la particularidad con la que cada indígena lo recorre. Más aún, en torno al territorio se ha constituido toda una estrategia política discursiva de representación de lo indígena ligada a dos ejes. Por un lado referenciando al territorio con prácticas ancestrales o como consecuencia "natural" de continuidad con el pasado y por otro lado en torno al cuidado medioambiental en contraposición con el modelo "destructivo" occidental (Ulloa, 2005). De este modo el territorio se carga estratégicamente de sentidos y argumentos comunes y con capacidad movilizadora, al tiempo que se vacía condenado a la homogeneidad del discurso indigenista y de la "ecopolítica" (Ulloa, 2001) que logró instalarlo como un tema de agenda tanto en la esfera internacional como nacional (García Hierro y Surrallés, 2004). Un colaborador pilagá sostenía:

\begin{abstract}
Como parte del pueblo pilagá, sería bueno que se haga mayor información en toda la provincia que está desconociendo todo ese tipo de terminología cuando se habla de territorio. Cuando hablamos de territorio nos estamos refiriendo no sólo al espacio geográfico que se conforma en una comunidad, sino que estamos hablando de una comunidad general, donde realmente existen hermanos aborígenes que habitan su propio lugar (dirigente pilagá de la comunidad de Qom Pi, comunicación personal, 2006).
\end{abstract}

Este discurso casi repetido de manera sistemática relaciona el territorio con algo que excede exclusivamente el espacio geográfico apelando a una "comunidad general" y a los "hermanos aborígenes". No obstante esta apelación se reviste de una significación muy abstracta a diferencia de las actividades concretas que los pilagá realizan con otros indígenas, para proveerse sustento, materia prima artesanal, o bien las que debieron discontinuar debido a la estrechez de las tierras, la degradación ambiental y la falta de acceso a determinados sitios, que es lo que se puso de manifiesto reiteradamente en mis estadías de campo.

Los pilagá, tal como Morita Carrasco (2010) sostiene con respecto a la producción política del territorio de los wichí pertenecientes a la Asociación de Comunidades Lhaka Honhat, desde sus experiencias cotidianas e históricas y como parte de una estrategia política enfatizaron un contrapunto permanente entre el pasado y el presente. Tal como señala este fragmento, el antes de un territorio recorrido y la diferencia con el actual como un acento del reclamo político: 


\begin{abstract}
Yo antes me iba a mariscar cuando era joven, tenía 18 años. Recorrimos largo, porque este campo era grandísimo para los aborígenes; grande para ir, para mariscar. Entonces la gente no piensa hacer las casas y quiere andar nomás. Total nosotros no vamos a necesitar nada, dice: 'hay para comer, hay toda clase de miel, hay pescado, hay carne de suri. ¿Qué necesidad tenemos?' Pero entonces no había alambre, había campo para ir a sacar la marisca, se puede entrar con tranquilidad, no había gente blanco. Cuando vino el colono que es agricultor ya empieza cortando la tierra (comunicación personal, 2011).
\end{abstract}

Si bien esta referencia a las prácticas del "antes", de cuando "era joven" les otorga la legitimidad del territorio tradicional conforme a las normativas en la materia, entra en tensión con las innovaciones, nuevas prácticas y diversos elementos propios de nuevos procesos sociopolíticos (Di Giminiani, 2012). Porque el discurso que a la vez legitima esas prácticas los fija en un pasado esencializado y asociado a prácticas milenarias que entran en tensión con contingencias propias de la contemporaneidad en la que también se enmarcan los derechos y reclamos indígenas como mejoras en el acceso a la salud y a la educación bilingüe.

El otro aspecto explotado discursivamente es la relación entre el territorio y los recursos naturales. Es por ello que a menudo estos indígenas enmarcaron su defensa territorial dentro de un discurso medioambientalista, construyéndose tanto como expertos ecólogos capaces de proteger el degradado ambiente, como destinatarios "naturales" de su cuidado. Un dirigente de Campo del Cielo sostuvo:

Los aborígenes somos los guardianes de la naturaleza, y se los voy a contar. Una vez vinieron cazadores de patos de Buenos Aries, equipados con freezer y todo. Nosotros los recibimos y los llevamos al bañado con los jóvenes, porque a veces ellos (refiriéndose a los turistas) necesitan guías, y porque nosotros sabemos dónde están los patos. Sin embargo, mataron 200 patos y sólo comieron el pecho y el resto todo lo tiraron. No son como los aborígenes que aprovechan todo, desperdician y no piensan que otra gente come, no ofrecieron en la escuela, dejaron todo nomás lo que no comían (comunicación personal, 2011).

Dentro del ideal de territorio pilagá asociado a la ecología, los qoselek fueron los depositarios de las críticas y quejas del deterioro del monte y del desperdicio. En espejo de ese deterioro se autoidentificaron los indígenas como "los guardianes de la naturaleza" que "saben" y en consecuencia no desperdician. De este modo la propuesta indígena se delinea en el campo del desarrollo sostenible y se inscribe el territorio en el marco de la "protección" propia de los 
discursos globales ambientales occidentales en contraposición con otro destructivo de la "Madre naturaleza" (Ulloa, 2001). Como sostuve, si bien estos qoselek que necesitaban guías pilagá fueron el blanco de las quejas o se delinearon en tanto "otros" destructivos, el destinatario último de este discurso político pilagá es el "Gobierno". El Estado provincial, y en segunda instancia el nacional, como los nuevos actores ante quienes reclamar el cumplimiento de los derechos reconocidos a los pueblos indígenas en las últimas tres décadas y en consecuencia disputar, reclamar, reconocer y negociar los territorios aborígenes ancestrales como parte de su política indígena y en el marco de sus nuevos derechos.

\section{Reflexiones finales}

Es inmenso el poder de ciertas palabras que evocan imágenes muy distantes y exóticas pero que pretenden ser límpidas y convincentes. Llenan el espacio de lo desconocido e inundan a quien las oye de expectativas y certezas que inmediatamente orientan su pensamiento y acción (Pacheco de Oliveira, 2006: 7).

Si bien Pacheco de Olivera (2006) escribió este fragmento en relación con los contenidos de los que se cargó a la palabra "indios", es paralelizable a lo que sucede en las últimas décadas con el concepto de territorio. Habida cuenta de su densidad en el presente artículo se planteó un recorrido en una doble dirección. Por un lado se analizó la política indigenista que la provincia de Formosa desplegó en materia de tierra desde el regreso a la democracia en 1983. Esta política indigenista referenciada en normativas internacionales, nacionales y provinciales ha titulado a nombre de las comunidades pilagá unas 33.000 hectáreas y constituyó un importante logro para la política indígena. No obstante una entrega de la tierra que hubiera respondido a los usos territoriales pilagá, hubiera implicado compras de tierras a terceros y una redistribución de las mismas que el gobierno provincial no estaba dispuesto a realizar y que los pilagá, como parte de su política indígena optaron en dicho momento por no reclamar.

En efecto, las formas de organización y la política indígena son en gran medida el producto paradojal de esta relación antagónica o complementaria con el Estado. Tal como sostiene Escolar (2007) en referencia con los huarpes, esas formas y condiciones de institucionalización, como se ha mostrado en la tramitación de personería jurídica a nivel provincial, deben ser nuevamente desafiadas para evitar la fijación legal y burocrática de su acción política, con el fin de mantener los delicados límites de su inclusión/exclusión en la 
estatalidad o normas políticas hegemónicas.

En este sentido, las diversas expresiones de las políticas indígenas consistieron en manifestaciones y presiones concretas para la sanción de la Ley Nro. 426/84, numerosas negociaciones a fin de amoldar la propia concepción de territorio a la escrituración de unos cientos de hectáreas, el desarrollo de determinadas habilidades burocráticas necesarias para gestionar el papeleo ante los organismos, entre otras.

De manera paralela al reclamo por ampliaciones y por el acceso a tierras que hasta hace unas décadas permanecían en estado fiscal y a las que se podía entrar y ahora ya no más, el territorio discursivamente y como parte también de una política indígena se ha cargado de sentidos desde los cuales se legitima el reclamo territorial. La construcción discursiva tiene dos pilares fundamentales la pertenencia histórica a ese territorio y la relación de respeto por la naturaleza de los indígenas. Estos discursos locales deben ser leídos también en el marco de discusiones globales sobre la política de reconocimiento y de derechos humanos (Langer y Muñoz, 2003; Ulloa 2005).

Los pilagá por un lado y en consonancia con los reclamos de los movimientos indígenas internacionales han vinculado al territorio discursivamente con parte su historia y en tanto legitimación en un "desde siempre" estuvimos aquí, inalterable a la luz de la historia y permeado de enseñanzas y prácticas ancestrales constitutivas de su identidad como pueblo. Por el otro, la construcción de un discurso legitimador de la pertenencia territorial se permeó la representación de los pilagá en tanto guardianes del medio ambiente y en tanto tales, sujetos designados, cuanto capacitados para su tenencia en el marco de una construcción política pilagá del territorio como parte constitutiva de su identidad y por lo tanto como un derecho inalienable.

\section{Notas}

(1) Los requisitos para la presentación consisten en "contar con un grupo de familias establecidas en un lugar determinado" y en Asamblea Comunitaria acordar la necesidad de crear una Asociación Civil sin fines de lucro. Para ello se debe labrar un Acta de Asamblea con una Comisión Directiva y Comisión Revisora de cuentas elegida en dicha Asamblea, aprobar un Estatuto Social con un objeto bien definido y amplio, presentar una Declaración Jurada de Patrimonio (aunque sea con lo recaudado a modo de cuota societaria en la Asamblea) y una Lista de socios (Instructivo de inscripción de la Dirección de Personería Jurídica para la Inscripción de Comunidades Aborígenes).

(2) Los libros requeridos son: "Libro de Acta de Asambleas, Libro de Actas de Reuniones de la Comisión Directiva, Libro Inventario, un Libro de Caja (de Estradas y Salidas), Libro de Socios" (Instructivo de inscripción de la Dirección de Personería Jurídica para la Inscripción de Comunidades Aborígenes). 
(3) Este proceso ha sido reconstruido, como parte de mi trabajo de campo etnográfico durante mis estadías en Formosa por personal del ICA.

\section{Bibliografía}

Beck, H. (1992). El régimen de tenencia de la tierra en las provincias del Chaco y de Formosa entre 1960 y 1990. El proceso de su adjudicación y su estado actual. Decimosegundo Encuentro de Geohistoria Regional, pp. 43-58, Resistencia.

Beck, H. (1994). Tratamiento legal del aborigen en Chaco y Formosa durante el siglo XX. Decimocuarto Encuentro de Geohistoria Regional, pp. 21-39, Resistencia.

Braunstein, J. (1984). Algunos rasgos de la Organización Social de los indígenas del Gran Chaco. Buenos Aires: Instituto de Ciencias Antropológicas, Facultad de Filosofía y Letras, Universidad de Buenos Aires.

Di Giminiani, P. (2012). Tierras ancestrales, disputas contemporáneas. Pertenencia y demandas territoriales en la sociedad mapuche rural. Chile: Universidad Católica de Chile.

Dirección de Personería Jurídica (2010). Instructivo de la Dirección de Personería Jurídica del Ministerio de Gobierno de la Provincia de Formosa para la inscripción de comunidades aborígenes. Ministerio de Gobierno, provincia de Formosa.

Escolar, D. (2007). Los Dones Étnicos de la Nación. Identidades huarpe y modos de producción de soberanía en Argentina. Buenos Aires: Prometeo.

García Hierro, P. y Surrallés, A. (2004). Introducción. En Surrallés, A. y García Hierro, P. (comps.). Tierra Adentro. Territorio Indígena y Percepción del Entorno. Serie de Documentos en Español, 39, (pp. 9-23). Lima: IWGIA.

Gómez, H. (1939). Historia de la Gobernación Nacional del Chaco. Resistencia: Publicación Oficial.

Gordillo, G. (1992). Cazadores-Recolectores y Cosecheros. Subordinación al capital y reproducción social entre los tobas del oeste de Formosa. En Trinchero, H.; Piccinini, D. y Gordillo, G. (comps.). Capitalismo y grupos indígenas en el Chaco CentroOccidental (2 vols.) (pp. 13-191). Buenos Aires: Centro Editor de América Latina (CEAL).

Gordillo, G. (2004). Landscapes of Devils. Tensions of Place and Memory in The Argentinean Chaco. Durham y London: Duke University Press. 
Gordillo, G. (2006). En el Gran Chaco: Antropologías e Historias. Buenos Aires: Prometeo Libros.

Gordillo, G. (2009). La clientelización de la etnicidad: hegemonía partidaria y subjetividades políticas indígenas. Revista Española de Antropología Americana, 39(2), pp. 247-262.

Gordillo, G. y Hirsch, S. (2003). Introduction: Indigenous Struggles and Contested Identities in Argentina. The Journal of Latin American Anthropology, 8(3), pp. 4-30.

Gordillo G. y Hirsch, S. (2010). La presencia ausente: invisibilizaciones, políticas estatales y emergencias indígenas en la Argentina. En Movilizaciones Indígenas e identidades en disputa en la Argentina (pp. 17-38). Buenos Aires: La Crujía.

Halperín Donghi, T. (1982). Una Nación para el desierto Argentino. Buenos Aires: Centro Editor de América Latina (CEAL).

Iñigo Carreras, N. (1983). La colonización del Chaco. Buenos Aires: Centro Editor de América Latina.

Iñigo Carreras, N. (1984). Campañas Militares y Clase obrera: Chaco, 1870-1930. Buenos Aires: Centro Editor de América Latina.

Lagos, M. (1998). Problemática del aborigen chaqueño. El discurso de la 'integración' 18701920. En Teruel, A.y Jerez, O. (comps.). Pasado y presente de un mundo postergado (pp. 57-102). San Salvador de Jujuy: Ed. UNJU y UNHIR.

Lagos, M. (2000). La cuestión indígena en el estado y la sociedad nacional. Gran Chaco: 18701920. San Salvador de Jujuy: Ed. UNJU.

Langer E. D. y Muñoz, E. (2003). Contemporary indigenous movements in Latin America. USA: Wilmington.

Lenton, D. (2010). La "cuestión de los indios" y el genocidio en los tiempos de Roca: sus repercusiones en la prensa y la política. En Bayer, O. (coord.) Historia de la Crueldad Argentina. Julio Argentino Roca y el genocidio de los Pueblos Originarios (pp. 29-50). Buenos Aires: El Tugurio.

Lois, C. (2002). De Desierto Ignoto a Territorio Representado. Cartografía, Estado y Territorio en el Gran Chaco Argentino (1866-1916). Cuadernos de Territorio, 10, Instituto de Geografía, Facultad de Filosofía y Letras, Universidad de Buenos Aires, Argentina.

Martínez Sarasola, C. (2005). Nuestros Paisanos los Indios. Vida Historia y Destino de las comunidades indígenas. Buenos Aires: Emecé.

Matarrese, M. (2011). Disputas y negociaciones en torno al territorio pilagá (provincia de Formosa). (Tesis de Doctorado en Antropología Social). Facultad de Filosofía y Letras, Universidad de Buenos Aires, Buenos Aires. 
Matarrese, M. (2013). Violando derechos y removiendo muertos: el caso del Bañado de la Estrella. En Tola, F.; Medrano, C. y Cardin, L. (comps.). Gran Chaco. Ontologías, poder, afectividad (pp. 133-152). Rumbo Sur/IGWIA: Buenos Aires, Argentina.

Matarrese, M. (2017). Qom Pi: Un territorio atravesado por la violencia entre lo propio y lo ajeno. Revista Publicar en Antropología y Ciencias Sociales. XV(XXII). pp. 25-44.

Pacheco de Olivera, J. (2006). Presentación. En Pacheco de Oliveira, J. (comp.). Hacia Una Antropología del Indigenismo. Estudios críticos sobre los procesos de dominación y las perspectivas políticas actuales de los indígenas en Brasil (pp. 7-14). Río de Janeiro: Contra Capa.

Pantaleón, J. (2005) Entre la carta y el formulario. Política y técnica en el Desarrollo Social. Buenos Aires: Antropofagia.

Pensamiento de los Indígenas de la Provincia de Formosa (PPI) (2003). Proceso de Participación de los Pueblos Indígenas (PPI), Centro de Capacitación zonal (CECAZO), Pozo de Tigre. Provincia de Formosa.

Spadafora, A. M.; Gómez, M. y Matarrese, M. (2010). Movilizaciones indígenas e identidades en disputa en la Argentina. Buenos Aires: La Crujía.

Trinchero, H. (2000). Los dominios del demonio: Civilización y Barbarie en las fronteras de la Nación. El Chaco Central. Buenos Aires: EUDEBA.

Ulloa, A. (2001). El nativo ecológico. Movimientos indígenas y medio ambiente en Colombia. En Archila, M. y Pardo, M. (comps.). Movimientos sociales, Estado y democracia en Colombia (pp. 286-320). Bogotá: Instituto Colombiano de Antropología e Historia (ICANH) y Centro de Estudios Sociales, Universidad Nacional de Colombia.

Ulloa, A. (2005). Las representaciones sobre los indígenas en los discursos ambientales y de desarrollo sostenible. En Mato, D. (coord.). Políticas de economía, ambiente y sociedad en tiempos de globalización (pp. 89-109). Caracas: Facultad de Ciencias Económicas y Sociales, Universidad Central de Venezuela. 